\title{
PENDEKATAN ANALISIS MORFOLOGI DALAM PEMBELAJARAN BAHASA ARAB
}

\author{
Muhammad Natsir \\ e-mail: m_nasir_79@yahoo.com \\ Universitas Islam Nahlatul 'Ulama' Jepara
}

\begin{abstract}
Arabic is a series of operations and processes train students to familiarize themselves to acquire skills / ability to understand everything that is heard, speaking, reading and writing in Arabic. One of proficiency is the skill to read and understand Arabic texts properly. However, in the practical realm is still encountered some problems and issues in this maharoh learning, students are still difficult to read or pronounce the word / phrase and find its meaning. This is because many students do not recognize and pronounce unfamiliar words based wazan (pronunciation rules) and sighot (type of word based dilalahnya). Of this problem researchers provide an alternative solution by presenting a pattern-based learning Arabic morphological analyzer. The objectives of this study were: 1) describe the procedures / technical-based learning Arabic morphology. 2) measure the effectiveness of pattern-based learning Arabic morphological analyzer in increasing reading competence. This study using a pre experimental design with a form of one-shot case Study. And the results of this study concluded that the pattern of learning is quite effective with indicators: 1) students are familiar and easy to pronounce and utter words corresponding wazan/shighot. 2) student easily to memory on vocabulary acquisition; origin of word and its meaning changes. 3) the students more easily and quickly understand a text with the stock of the results of the acquisition of vocabulary and understanding of the meaning of the vocabulary.
\end{abstract}

Keywords: approaches, Morphology, Learning Arabic

\section{PENDAHULUAN}

Termasuk karakteristik bahasa Arab adalah bahasa Isytiqoq (terdapat asal usul kata dan perubahan bentuk kata) dan bahasa yang kaya dengan suara bunyi fonemnya sesuai dengan perubahan bentuk aturan bunyinya (wazan). Oleh karena itu, setiap kata memiliki wazan pada setiap pengucapanya. Ketika kita membaca teks arab kita memperhatikan wazan shorofnya dalam pengucapan dan pelafalan agar bacaannya menjadi benar pada maksud yang diharapakan dan dilogikakan.

Mencermati wazan-wazan pada setip kata dalam bahasa arab, terdapat sekitar 29 wazan morfologis yang mencakup kata kerja yang terdiri dari 3 huruf, 4 huruf, 5 huruf dan 6 huruf. Dan mungkin setiap kata kerja berubah dari satu bentuk ke bentuk yang lain dan satu asal kata ke yang lainnya. Kita pernah membaca dan mencermati satu kitab yang berjudul amtsila al-tashrifiyyah karangan syaikh ali maksum lirboyo kediri, beliau mencontohkan bahwa satu kata dapat berubah bunyi pelafalan dan maknanya sesuai yang dimaksudkan, sebagai contoh, di kitab tersebut dicontohkan satu kata dari bentuk fi'il madhi (waktu lampau) ke - mudhorik (wkt sekarang dan akan datang) - masdar (kt.nominal, proses terjadinya pekerjaan) - isim fa'il (yang melakukan pekerjaan) - isim maf'ul (yang dikenai pekerjaan) - fi'il amar (perintah) - fi'il nahi (larangan) - isim zaman (ket. Waktu) - isim makan (ket.tempat) - isim alat (kt.menunujukkan alat). Pemahaman terhadap perubahan wazan kata menjadi penting dimiliki oleh pembelajar bahasa Arab sebagai kesiapan untuk membaca teks-teks berbahasa Arab. Begitu juga hal yang harus dilakukan adalah membiasakan mencermati asal pokok kata, memahami dan menemukan 
maknanya sesuai konteks yang dimaksudkan.

Hal yang penting juga adalah mencermati dan menemukan opini dalam suatu kalimat dengan cara menemukan dan menentukan jabatan kata dalam kalimat dan selanjutnya mengkombinasikannya sehingga sampai pada ketepatan melafalkan bunyi setiap kata berdasarkan wazan dan sesuai dengan pemahaman makna yang dimaksudkan.

Problem yang muncul, sebagian kita tidak memperhatikan konteks dan keadaan tersebut, bahkan sebagian hanya lebih memperhatikan analisis sintaksis (ilmu nahwu); mencermati susunan kalimat, jabatan kata dalam kalimat dan konteksnya saja, dan selanjutnya untuk memahami teks berbahasa arab terdapat prosedur yang bervariasi, prosedur pertama mengikuti langkah; 1) mencermati kata dan kalimat. 2) menemukan konsep dengan memperhatikan aturan melafalkan setiap kata, dan 3) selanjutnya memahami dan menemukan konsep/opini dalam konteks kalimat/paragraf tersebut. Prosedur kedua adalah sebagian mampu menemukan makna dalam kalimat akan tetapi kurang tepat dalam melafalakan setiap kata dalam kalimatnya, dan juga belum mampu untuk melafalkan setiap kata sesuai dengan wazan (aturan pelafalan).

Dari problem yang muncul tersebut - menjadi satu faktor - disebabkan karena belum membiasakan untuk menerapkan wazan dan sighot (jenis kata) pada suatu kata ketika membaca, dan hal ini perlu disikapi dengan mendesain model pembelajaran dengan cara membiasakan menerapkan wazan pada suatu kata; mencermati dan menemukan asal pokok dari suatu kata kemudian menemukan perubahan setiap kata sesuai dengan wazan (aturan bunyi kata) dan shighotnya (formula/jenis kata). langkah ini dilakukan untuk menemukan makna kata dan kalimat, dan hal ini dimaksudkan untuk meningkatkan kemampuan membaca. Pola pembelajaran ini memiliki urgensi yang berlandaskan pada falsafah bahwa bahasa adalah bunyi suara yang berupa simbol-simbol kebahasaan.

Dari beberapa problem yang telah dipaparkan, maka peneliti berusaha memberikan alternatif pola dalam pembelajaran bahasa Arab, yaitu desain dan penerapan pendekatan analisis morfologi dalam pembelajaran bahasa Arab. Pola pembelajan ini dipraktekkan bagi siswa untuk melatih siswa dalam mengujarkan kata sesuai dengan wazan dan sighotnya serta maknanya, dan melatih siswa untuk menemukan asal muasal kata dan perubahan maknanya, serta melatih siswa untuk mampu memahami teks dengan bekal pemahaman makna kata yang telah diprolehnya. Penulis menerapkan pola pembelajaran seperti ini bermaksud untuk Untuk mengetahui efektifitas pola pembelajaran dengan pendekatan analisis morfologi Dalam meningkatkan maharoh Qiro'ah dalam pembelajaran bahasa Arab.

\section{METODE PENELITIAN}

Jenis penelitian yang digunakan adalah kualitatif dan kuantitatif dengan desain eksperimen; pre ekperimental, karena masih ada variabel luar yang ikut beerpengaruh terhadap terbentuknya variabel dependen. Jadi hasil eksperimen yang merupakan variabel dependen itu bukan semata- mata dipengaruhi oleh variabel independen. Hal ini dapat terjadi, karena tidak adanya variabel kontrol, dan sampel tidak dipilih secara random. Bentuk desain ini menggunakan one shot case studi, yaitu paradigma dalam penelitian yang dapat digambarkan seperti berikut:

$\mathrm{X} \mathrm{O} \quad \mathrm{X}=$ treatment yang diberikan (varibel independen) 
(variabel dependen)

$$
\mathrm{O}=\quad \text { Observasi }
$$

Paradigma tersebut dapat dibaca $=$ terdapat suatu kelompok diberi perlakuan, dan selanjutnya diobservasi hasilnya (treatment adalah sebagai variabel independen, dan hasil adalah sebagai variabel dependen). ${ }^{1}$

\section{HASIL DAN PEMBAHASAN}

\section{Ilmu Sharaf (Morfologi Bahasa Arab)}

Kata Al-shorfu dan al-tashrif keduanya berbentuk masdar, dalam bahasa arab bermakna merubah, shorof menjadi satu cabang ilmu, dan orang yang pertama kali membahas cabang ini adalah abu al-muslim al-harro'. Selanjutnya shorof didefinisikan sebagai kaidah untuk mengetahui seluk beluk konstruksi kata, selain i'rob, seperti tatsniyah (bermakna 2), jamak (bermakna banyak), tashghir (bermakna sedikit/kecil), nasab (jenis/marga), dan i'lal (proses penelusuran asal muasal kata berdasarkan kaidah yang berlaku), shorof masuk pada ranah isim, fi'il dan bukan pada huruf dan semisalnya. ${ }^{2}$ Para linguist arab klasik mendefinisikan shorof sebagai pengetahuan terhadap dasar-dasar untuk mengetahui seluk-beluk kostruksi kata yang i'rob (perubahan) atau binak (tetap/statis), yaitu beberapa perubahan yang terjadi pada suatu kata; perubahan asal kata yang pertama ke beberapa contoh-contoh yaang berbeda seperti isim fa'il, isim maf'ul, isim tafdhil, tastniyah, jamak, shahih, i'lal dan asal, tambahan dan lainnya. ${ }^{3}$ Menurut al-Ghalayayni (1987: 9) 'ilm al-sharf adalah ilmu yang membahas dasar-dasar pembentukan kata,

\footnotetext{
${ }^{1}$ Sugiyono, Metode penelitian Kuatitatif kualitatif dan R\&D, Alfabeta, Bandung, 2012, hal 74

${ }^{2}$ Harun al-azhari ibn abdi al-rozaq., Tt, unwanu al-dzorfi, al-hidayah, surabaya, hal 5

${ }^{3}$ khilmi kholil, muqoddimah lidirosati al-lughoh, dar al-makrifah, iskandariyah, 1996, hal 245
}

termasuk di dalamnya imbuhan. ${ }^{4}$ Sharaf memberikan aturan pemakaian masingmasing kata dari segi bentuknya yang dikenal dengan Morfologi. Dengan kata lain bahwa sharaf memberikan aturan pemakaian dan pembentukan kata-kata sebelum digabung atau dirangkai dengan kata-kata yang lain.

Bahasa Arab adalah bahasa yang pola pembentukan katanya sangat beragam dan fleksibel, baik melalui cara derivasi (tashrif isytiqaqy) maupun dengan cara infleksi (tashrif i'raby). Dengan dua cara tersebut, bahasa Arab menjadi sangat kaya dengan kosakata.

Bahasa Arab dari segi pengembangan makna gramatikal ditandai dengan Isytiqaq, yang menjadikan katakata Arab berubah secara elastis dalam kata itu sendiri. Dari satu kata سلم dan

سلامة menjadi jumlah kata seperti berikut ini:

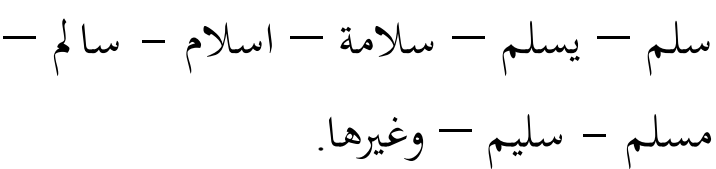

Bahasa Arab termasuk bahasa yang infleksi, pengembangan makna gramatikal dilakukan dengan cara mengembangkan satu bentuk menjadi sejumlah bentuk untuk menunjukan variasi makna yang berbeda. Lain halnya dalam bahasa Indonesia dan bahasa Inggris, yang dalam pengembangan makna gramatikalnya banyak mengandalkan proses afiksasi (awalan, akhiran, sisipan), dan reduplikasi (pengulangan), seperti pada tabel di atas. Dari perbandingan itu tampak bahasa Arab lebih ajeg (qiyasi) dalam pemahaman makna, dan lebih simpel bentuk pengembangannya (ijaz), karena perubahan terjadi secara internal, tidak

\footnotetext{
${ }^{4}$ Lihat Aziz Fachrurrozi, Erta Mahyudin., Teknik Pembelajaran Bahasa Arab, Lembaga Bahasa Yassarna YBMQ Jakarta, hlm. 55.
} 
perlu banyak mengandalkan afiksasi atau reduplikasi. $^{5}$

\section{Pokok Pembahasan Morfologi Bahasa Arab (Tashrif al-Ishthilahiy wa Lughowy)}

Bahasan linguistik -pada ranah selain struktur- adalah kata, ilmu shorof memperhatikan studi konstruksi kata dari beberapa aspek berikut:

a) Isytiqoq (derivasi) dari beberapa bentuk yang berubah-ubah dari asal yang satu, contoh: (ka ta ba), kaatibun, maktuubun, kitabah, maktab, maktabah dst.

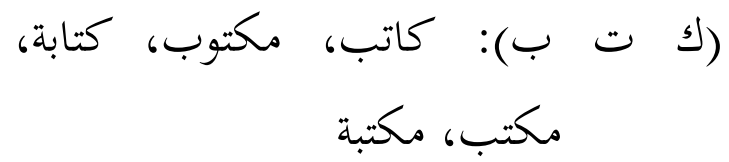

b) Perubahan yang terjadi pada kata; penambahan dan pengurangan.

1) Perubahan pada penambahan: prefixes, suffixes, dan infixes yang menemui kata dan menyebabkan pada perubahan makna, di sini ada perbedaan jelas antara huruf asal dan huruf tambahan, awalan seperti pada fi'il mudhorik yang dalam bahasa bahasa Arab terkumpul dalam kata (alif, nun ya' dan ta'), suffixes seperti tanda tatsniyah:(makna dua).

$$
\text { عالمين - عالمان }
$$

dan jamak عالمون- عالمين, suffixes seperti: alif tanda jamak taksir (رجال ) ta' wazan افتعال)

$$
\text { (التزام) }
$$

2) Perubahan pada pengurangan: hal ini bisa dicermati pada proses i'lal, terkadang dengan membuang huruf dari kata, yaitu ada dua macam:

a) Membuang secara sima'i (diambil dari lisan/produk arab): terbatas pada kata yang

\footnotetext{
${ }^{5}$ Ibid. hlm. 17-18.
}

dibuang huruf akhirnya, dan tidak ada kaidahnya, seperti:

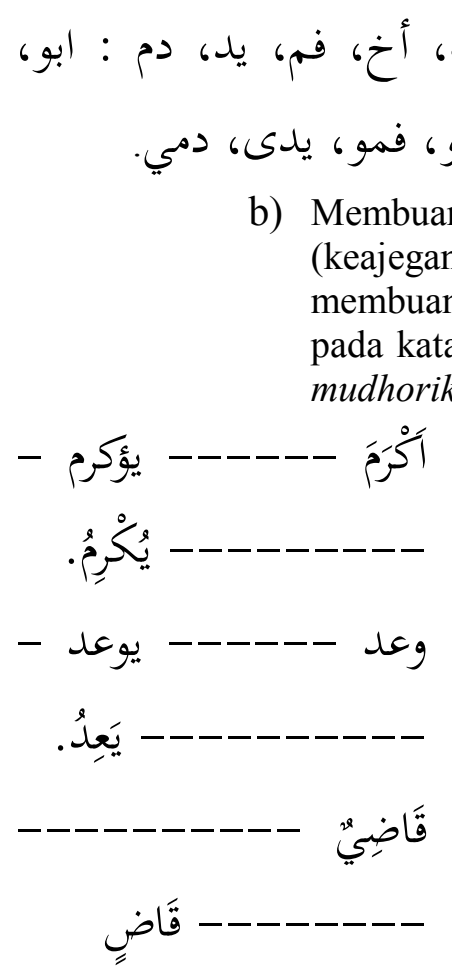

Cakupan yang dibahas dalam morfologi bahasa Arab umumnya terkait dengan bentuk dan perubahan bentuk (tashrif istilahy); fi'il madhi, fi'il mudhari, mashdar, isim fa'il, isim maf'ul, isim zaman, isim makan, isim alat, dan (tasrif Lughowy); bentuk mufrod, tatsniyyah dan Jamak serta muntahal jumuk (jamak dari jamak).

\begin{tabular}{|c|c|c|c|c|c|c|c|c|c|}
\hline لم & الم & الزم الم & فعل & ل & لهم & ل & ص صر & ضار & ضى الما \\
\hline $\begin{array}{l}\text { ف } \\
\text { ف } \\
\text { ف }\end{array}$ & تح & تح & تف & فُ & توح & تح & | & يفتح & فتح \\
\hline
\end{tabular}

Contoh Tahsrif al-Ishthilahiy:

${ }^{6}$ Muhammad Muhammad dawud, al-arobiyyah wa ilmu al-lughoh al-hadits, Dar gharib, kairo, 2001, hal 161. 


\begin{tabular}{|c|c|c|c|c|c|c|c|c|c|}
\hline- & محرم & محرم & تلار & $\begin{array}{l}> \\
>\end{array}$ & محرم & محرم & ما احرا & يكرم & احرم \\
\hline- & ترم & ترم & تلا & ترم & محترم & ترم & | & يكترم & ترم \\
\hline- & تفاد & تفاد & لات & ' & تفاد & تفيد & | & تفيد & تفاد \\
\hline
\end{tabular}

Ket: terkadang juga disebutkan masdar mim, yaitu masdar yang awal kata diawali dengan huruf mim, seperti kata diatas menjadi maftahan, mahroman, muhtaroman, dan mustafadan.

Contoh tashrif lughowi (bentuk mufrod, tatsniyyah dan jamak) :

\begin{tabular}{|c|c|c|c|c|}
\hline الفاعل & فعل امر & فعل & فعل & دلالة \\
\hline فاتح & - & يفتح & فتح & هو \\
\hline فاتحان & - & يفتحان & فتحا & هما \\
\hline فاتحون & - & يفتحون & فتحوا & هم \\
\hline فاتحة & - & تفتح & فتحت & هي \\
\hline فاتحتان & - & تفتحان & فتحتا & هم \\
\hline فاتحات & - & يفتحن & فتحن & هن \\
\hline- & افتح & تفتح & فتحتَ & انت \\
\hline- & افتحا & تفتحان & فتحتما & انتما \\
\hline- & افتحوا & تفتحون & فتحتم & انتم \\
\hline- & افتحي & تفتحين & فتحتِ & انت \\
\hline
\end{tabular}

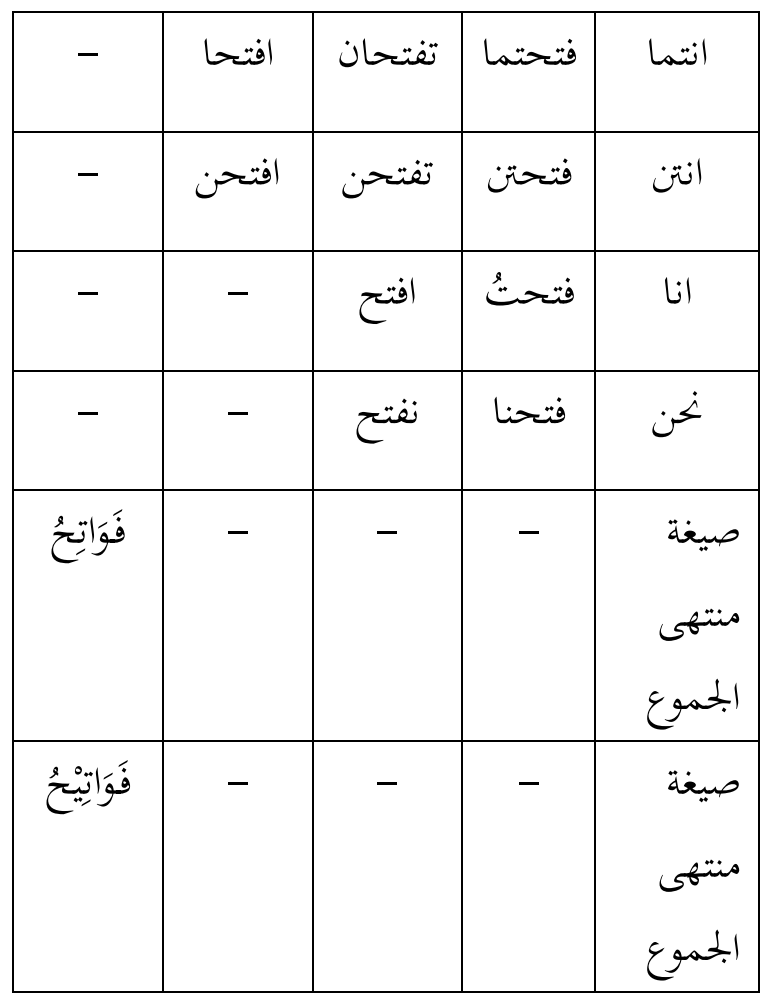

Dari pemaparan terkait morfologi, maka ilmu tersebut sangat berperan dalam pembelajaran pada maharoh Qiro'ah, yaitu bagaimana pembelajar mengujarkan kata/kosakata dengan ujaran yang benar dan sesuai dengan aturan pelafalan bunyi kata yang berlaku pada kaidah bahasa Arab. Begitu juga ilmu ini sangat berperan bagi pembelajar bahasa Arab dalam menemukan makna suatu kata berdasarkan pada sighot (pelafalan ujaran kata berdasarkan makna yang ditunjukkan oleh kata tersebut/dilalahnya. Sehingga secara bertahap pembelajar bahasa Arab akan melalui beberapa tahapan/strata dalam mempelajari bahasa Arab pada kemahiran membaca.

Adapun strata di sini adalah tingkatan kemampuan dalam membaca. Hal ini menjadi pegangan bagi pengajar dalam mengajarkan membaca untuk membantu keberhasilan dari tujuan. Ada tiga strata dalam membaca: 
a) Strata pemula: membentuk kecermatan siswa terhadap bahasa (simbol)

b) Strata menengah: fokus pada penguasaan kosakata bagi siswa dan mengembangkan kecermatannya pada struktur bahasa, bacaan diperluas pada tema-tema tertentu.

c) Strata perkembangan: pada strata ini siswa berlatih mandiri untuk mengembangkan kosakata, dan belajar bagaimana menggunakan kamus dan diawali dengan kemandirian/kebebasan dalam membaca. ${ }^{7}$

Model pembelajaran: implementasi analisis morfologi dalam pembelajaran

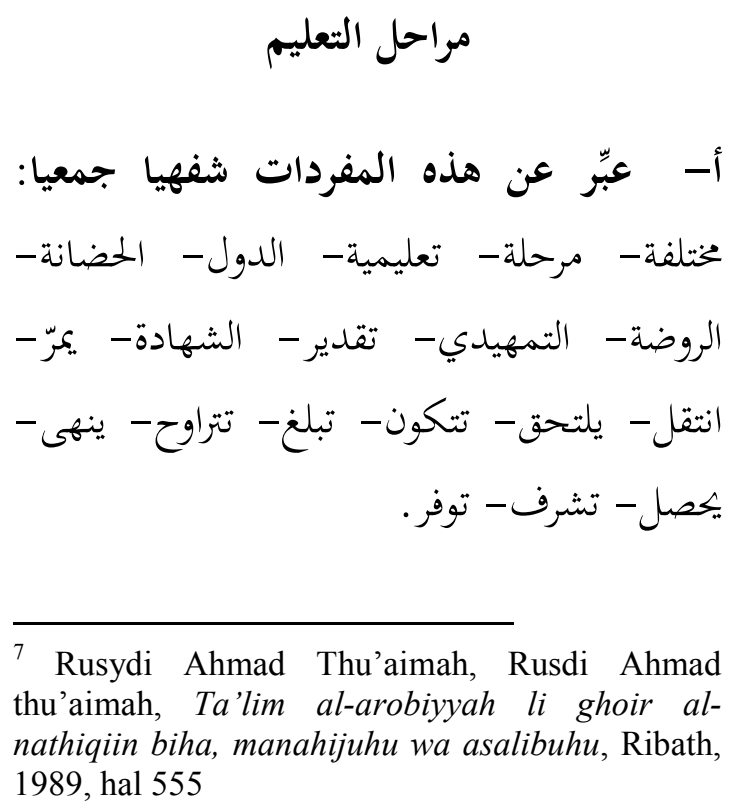

ب- تحليل الكلمات حسب اشتقاقها: على طريقة أمثلة تصريفية للشيخ على معصوم لييربايا كديري

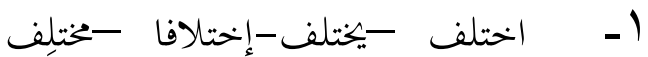

- مختلف -اختلف - الا تختلفمختلف - مختلف

Y - رحل - يرحل - رحلة الى صيغة

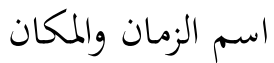

"- علّم - يعلّم - تعليم الى صيغة اسم

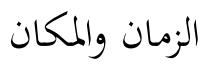

ع - مهّد - ميكهد - تمهيد الى صيغة اسم الزمان والمكان

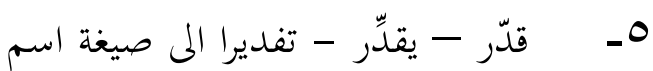

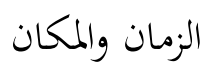

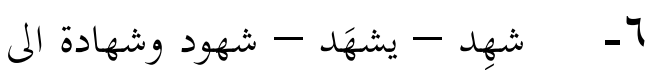
صيغة اسم الزمان والمكان

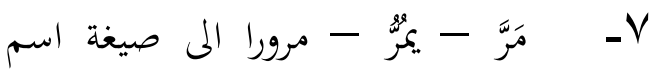
الزمان والمكان

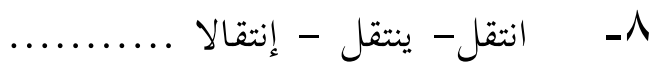
الى صيغة اسم الزمان والمكان 9 - ـ - التحق - يلتحقُ - إلتحاقا المى صيغة اسم الزمان والملكان التحسي • 1 - تكوّن- يتكوَّن - تكوّنا.. الى صيغة اسم الزمان والمكان 


$$
\begin{aligned}
& 11 \text { - بلغ - تبلغ - بلوغا- الى صيغة اسم }
\end{aligned}
$$

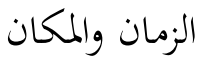

$$
\begin{aligned}
& \text { ץ ا - تراوح - تتراوح - تراوحا الى صيغة }
\end{aligned}
$$

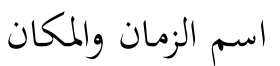

$$
\begin{aligned}
& \text { سا - - اهى - يُنِِى - إناءا. المى صيغة }
\end{aligned}
$$

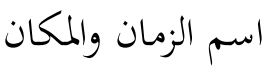

$$
\begin{aligned}
& \text { ع ا- - مصل - يكصل - حصولا- الى الى } \\
& \text { صيغة اسم الزمان والمكان }
\end{aligned}
$$

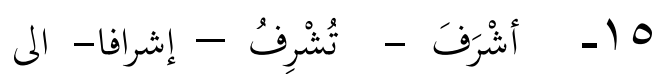

$$
\begin{aligned}
& \text { صيغة اسم الزمان والمكان }
\end{aligned}
$$

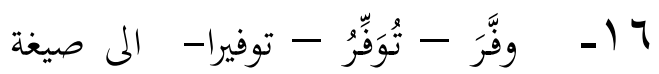

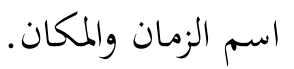

$$
\text { ج- قراءة }
$$

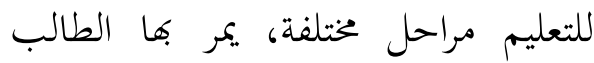

خلال دراسته، فإذا أفهى مرحلة تعليمية، انتقل إلى المرحلة التي بعدها. وتتكون مراحل التعليم في كثير من الدول العربية من أربع مراحل؛ هي: المرحلة الابتدائية، فالمرحلة المتوسطة، فالمرحلة الثانوية، ثم المرحلة الجامعية. وفي بعض البلاد العربية، يلتحق التلاميذ قبل المدرسة الابتدائية بالحضانة، فالروضة،

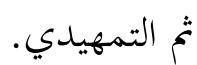

يلتحق التلاميذ بالمدرسة الابتدائية - عادة - في السادسة من أعمارهم. وتبلغ سنوات الدراسة في المرحلة الابتدائية ست سنوات. وتبلغ سنوات الدراسة في المرحلة المتوسطة ثلاث سنوات، وكذلك
في المرحلة الثانوية. أما المرحلة الجحامعية، فتتراوح بين أربع وست سنوات.

بعد أن ينهي الطالب المرحلة الثانوية، يلتحق بالجامعات، أو المعاهد، إذا حصل على بلى تقدير طيب. وبعد أن يحصل الطالب على الشهادة

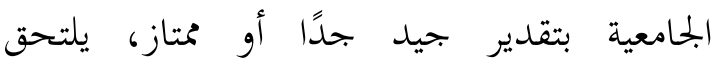
بالدراسات العليا؛ للحصول على شهادة الماجستير، ثم شهادة الدكتوراه.

من ناحية أخرى، في البلاد العربية نوعان من

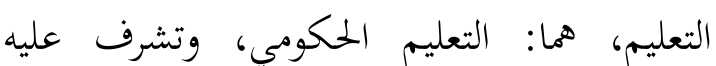
الدولة؛ فتبنى المدارس ، وتوفر الكتب والمدرسين، والتعليم الأهلي، وتشرف عليه بعض الجمعيات والأفراد.

\section{د- أجب عن الأسئلة التالية !}

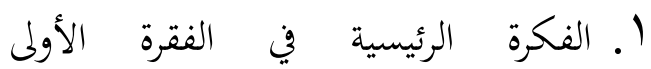

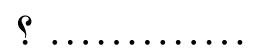

Y. الفكرة الرئيسية في الفقرة الثانية

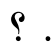

ب. الفكرة الرئيسية ي الفقرة الثالثة @ ............. ع. كم نوعا من التعليم في العربية @.............. ○. كم سنة من التعليم في مرحلة جامعية $ৎ \ldots \ldots .$. 


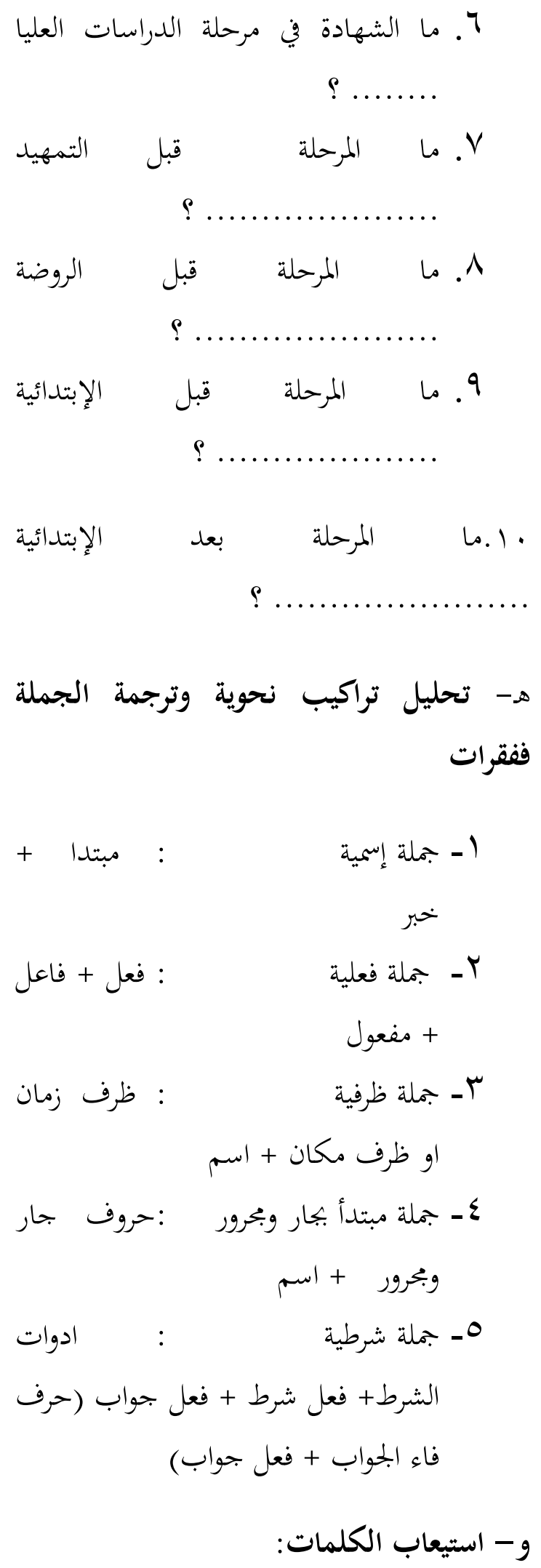

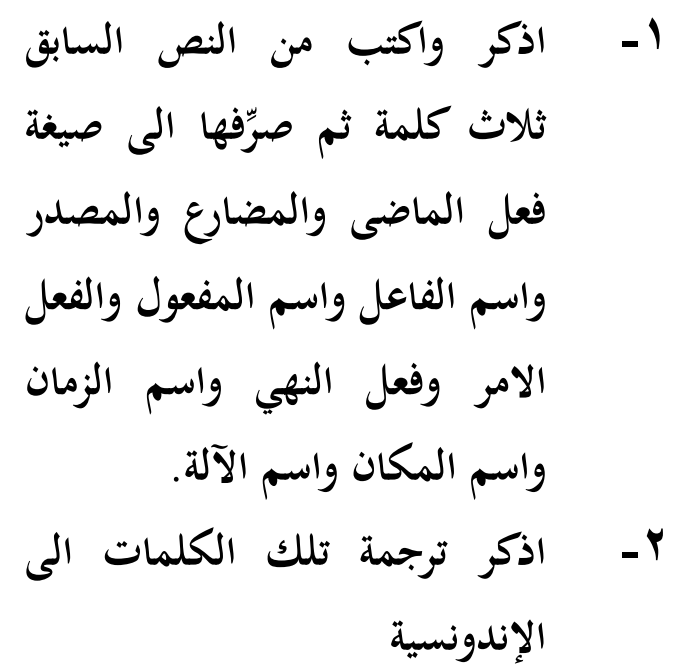

Dari pola penerapan pembelajaran yang telah dipaparkan di atas, maka selanjutnya diukur efektifitasnya dalam pembelajaan bahasa Arab.

Sedangkan data yang diambil adalah berupa hasil observasi dan evaluasi dari penerapan pola pembelajaran bahasa arab dengan pendekatan analisis morfologi. Observasi merujuk pada kriteria yang terkait dengan:

1. minat dan keaktifan mahasiswa selama perkuliahan.

2. Data kemajuan mengenal wazan/sighot dari suatu kata.

3. Data mengenal, memahami dan menghafal serta menganalisis asal mausal kata, perubahan kata (tashrif), dan makna kata.

4. Serta data kemajuan dalam menerjemahkan kalimat/teks.

Sedangkan evaluasi berdasarkan pada hasil atau nilai tes yang mengukur kemampuan mahasiswa dari aspek; 1) kompetensi membaca, dan 2) kompetensi analisis kata berbasis analisis morfologi (ilmu shorof). Setelah data diurutkan dan diolah, maka ditemukan hal berikut:

1) bahwa nilai rata-rata mahasiswa pada kompetensi membaca memahami teks bacaan adalah 65,42 . ( $2.5=$ Cukup baik ) 
2) Nilai rata-rata mahasiswa pada kompetensi analisis morfologi adalah 83,3.1 $(4.0=\mathrm{A})$

3) Dan Nilai rata-rata mahasiswa pada kompetensi membaca dan analisis morfologi adalah 74,36 . ( $3.3=\mathrm{B}$ )

Maka dari analisis data ini dapat disimpulkan bahwa hasil dari penerapan pola pembelajaran ini memberikan pengaruh yang cukup signifikan terhadap pengembangan kompetensi mahasiswa pada kemampuan mengujarkan setiap kosakata, menemukan makna dan menerjemahkan kalimat atau teks bacaan serta menemukan opini pokok yang terkandung di dalam teks tersebut.

\section{SIMPULAN DAN SARAN}

Pola pembelajaran bahasa arab dengan tahapan-tahapan; 1) mempresentasikan kosakata, 2) menganalisis asal muasal kosakata dengan menemukan perubahan wazan/shigot dan maknanya, 3) menemukan bentuk mufrod, tastniyah, dan jamak, 4) membaca dan memahami teks bacaan dengan cara menjawab pertanyaan, 5) menerjemahkan kalimat/teks, 6) menemukan opini pokok isi teks, adalah cukup efektif dan dapat meningkatkan kompetensi membaca bagi mahasiswa. Akan tetapi, pola pembelajaran ini memiliki beberapa kelemahan, diantaranya adalah:

1) Terkesan monoton dan cenderung menyebabkan kebosanan.

2) Memerlukan waktu yang relatif lama.

3) Menekan mahasiswa dalam menghafalkan wazan-wazan dalam ilmu shorof.

4) Belum mencapai sasaran dalam memahami secara komprehensif terkait penggunaan kosakata dalam kalimat.
Penelitian ini berimplikasi terhadap upaya membekali mahasiswa dalam menempuh mata kuliah bahasa arab selanjutnya, yaitu bahasa arab untuk skill mendengarkan, berbicara dan skill menulis. Karena pembelajaran bahasa arab bersifat gradual dan berkesinambungan, yakni harus tuntas dalam menempuh satu strata untuk melangkah pada satu strata berikutnya, sehingga pembekalan awal sebagai pondasi dan dasar dalam mempelajari bahasa merupakan prioritas untuk mencapai target kurikulum yang telah dirumuskan.

Kesempatan, waktu dan yang lainnya menjadi salah satu keterbatasan peneliti untuk melakukan penelitian pada skala yang lebih luas cakupannya. Oleh karena itu, penelitian ini perlu dikembangkan lebih lanjut oleh penelitian yang serupa secara berkesinambungan.

\section{DAFTAR PUSTAKA}

Ahmad Thu'aimah, Rusydi. 1989. Ta'lim al-arobiyyah li ghoir al-nathiqiin biha, manahijuhu wa asalibuhu. Makkah: Ribath

Fachrurrozi, Aziz, Mahyudin, Erta. Tt. Teknik Pembelajaran Bahasa Arab. Jakarta: Lembaga Bahasa Yassarna YBMQ

Harun al-azhari ibn abdi al-rozaq. Tt. unwanu al-dzorfi. Surabaya: alhidayah

Kholil, khilmi. 1996. muqoddimah lidirosat al-lughoh. Iskandariyah: dar almakrifah

Muhammad Muhammad dawud. 2001. alarobiyyah wa ilm al-lughoh alhadits. Kairo: Dar gharib

Sugiyono. 2012. Metode penelitian

Kuatitatif kualitatif dan R\&D. Bandung: Alfabeta

\section{Implikasi dan Keterbatasan Peneliti}

